\title{
LIVER TRANSPLANTATION IN A RANDOMIZED CONTROLLED TRIAL OF EMERGENCY TREATMENT OF ACUTELY BLEEDING ESOPHAGEAL VARICES IN CIRRHOSIS
}

\author{
Marshall J. Orloff ${ }^{a}$, Jon I. Isenberg ${ }^{b}$, Henry O. Wheeler ${ }^{b}$, Kevin S. Haynes ${ }^{b}$, Horacio Jinich- \\ Brook $^{\mathrm{b}}$, Roderick Rapier ${ }^{\mathrm{b}}$, Florin Vaida ${ }^{\mathrm{c}}$, Robert J. Hye ${ }^{\mathrm{a}}$, and Susan L. Orloff ${ }^{\mathrm{d}}$ \\ a Department of Surgery, University of California, San Diego Medical Center, San Diego, \\ California \\ b Department of Medicine/Gastroenterology, University of California, San Diego Medical Center, \\ San Diego, California \\ c Department of Family and Preventive Medicine/Biostatistics and Bioinformatics, University of \\ California, San Diego Medical Center, San Diego, California \\ d Division of Abdominal Organ Transplantation, Department of Surgery, Oregon Health and \\ Sciences University, Portland, OR
}

\section{Abstract}

Background-Bleeding esophageal varices (BEV) in cirrhosis has been considered an indication for liver transplantation (LT). This issue was examined in a randomized controlled trial (RCT) of unselected, consecutive patients with advanced cirrhosis and BEV that compared endoscopic sclerotherapy (EST) $(n=106)$ to emergency direct portacaval shunt (EPCS) $(n=105)$.

Methods-Diagnostic workup and treatment were initiated within 8 hours. Patients were evaluated for LT on admission and repeatedly thereafter. $96 \%$ underwent over 10 years of regular follow-up. The analysis was supplemented by 1300 unrandomized cirrhotic patients who previously underwent portacaval shunt (PCS) with 100\% follow-up.

Results-In the RCT, long-term bleeding control was 100\% following EPCS, only $20 \%$ following EST. 3, 5, 10, and 15-year survival rates were 75\%, 73\%, 46\%, and 46\% following EPCS, compared to $44 \%, 21 \%, 9 \%$, and $9 \%$ following EST (p<0.001). Only 13 RCT patients ( $6 \%$ ) were ultimately referred for LT mainly because of progressive liver failure; only $7(3 \%)$ were approved for LT and only 4 (2\%) underwent LT. 1- and 5-year LT survival rates were $0.68 \%$ and 0 , compared to $81 \%$ and $73 \%$ after EPCS. In the 1300 unrandomized PCS patients. 50 (3.8\%) were referred and $19(1.5 \%)$ underwent LT. Five-year survival rate was $53 \%$ compared to $72 \%$ for all 1300 patients.

Conclusions-If bleeding is permanently controlled, as occurred invariably following EPCS, cirrhotic patients with BEV seldom require LT. PCS is effective first-line and long-term treatment. Should LT be required in patients with PCS, although technically more demanding, numerous

Corresponding author: Marshall J. Orloff, M.D., Distinguished Professor and Chair of Surgery, Emeritus, UCSD Medical Center, 200 West Arbor Drive, San Diego, CA 92103-8999 U.S.A., Tel. No. 619-543-5865, Fax 619-543-6253, morloff@ucsd.edu.

Publisher's Disclaimer: This is a PDF file of an unedited manuscript that has been accepted for publication. As a service to our customers we are providing this early version of the manuscript. The manuscript will undergo copyediting, typesetting, and review of the resulting proof before it is published in its final citable form. Please note that during the production process errors may be discovered which could affect the content, and all legal disclaimers that apply to the journal pertain. 
studies have shown that PCS does not increase mortality or complications. EST is not effective emergency or long-term therapy.

\section{Keywords}

Portacaval shunt; endoscopic sclerotherapy; liver transplantation; survival

\section{INTRODUCTION}

Bleeding esophageal varices (BEV) in patients with cirrhosis of the liver are common and highly lethal [1]. Extensive data have shown that the period surrounding the episode of acute bleeding accounts for much of the mortality rate associated with BEV [1-10]. Emergency treatment of BEV, therefore, is of singular importance in the care of patients with cirrhosis. Nevertheless, few randomized trials of emergency treatment, including surgical therapy have been reported.

Liver transplantation (LT) is the only curative treatment of cirrhosis. Some transplant centers have considered BEV in cirrhosis to be an indication for LT. It has been proposed that LT be considered the treatment of choice for "patients with advanced liver disease after failure of sclerotherapy" $[11,12]$ and for "all patients with end-stage liver disease (group C) and variceal bleeding... in the absence of any contraindications" [11-13]. Regrettably, there have been no randomized controlled trials of LT following any of the emergency modalities of therapy for BEV to support or contradict these proposals. All reported data on LT in patients with BEV have been based on retrospective reviews of medical records.

Furthermore, recommendations regarding LT in patients with BEV generally have not taken into account the well known limitations, particularly insufficient donor organs.

From April 8, 1988, to December 31, 2005, we conducted a randomized controlled trial (RCT) in 211 unselected, consecutive patients with cirrhosis and acute BEV in whom emergency and long-term endoscopic sclerotherapy (EST) was compared to emergency direct portacaval shunt (EPCS). The trial was a community-wide endeavor and was known as the San Diego Bleeding Esophageal Varices Study. In two recent publications, we described the study in detail and reported the outcomes first with regard to control of bleeding and survival [14], and second with regard to development of portal-systemic encephalopathy (PSE) [15]. This report examines the question of the need for LT after the life-threatening problem of BEV has been addressed. In addition, the effect of EST or EPCS on the conduct and outcome of LT is examined.

As a supplement to the RCT data, we have analyzed our results regarding LT in 1300 unrandomized patients in whom we performed portacaval shunt (PCS) beginning in 1978, 600 as an emergency PCS and 700 electively.

\section{PATIENTS AND METHODS \\ Design of Randomized Controlled Trial}

Our two recent publications [14,15] described our RCT and provided full information on the protocols and methods. These include (1) design of study; (2) patient eligibility; (3) definitions (bleeding esophageal varices (BEV), unselected patients ("all comers"), emergency endoscopic sclerotherapy (EST), long-term endoscopic sclerotherapy (EST), emergency portacaval shunt (EPCS), failure of emergency primary therapy, failure of longterm therapy, rescue therapy, informed consent; (4) randomization; (5) diagnostic work-up; (6) quantitative Child's classification; (7) initial emergency therapy during workup; (8) endoscopic sclerotherapy; (9) emergency portacaval shunt; (10) posttreatment therapy; (11) 
lifelong follow-up; (12) quantitation of portal-systemic encephalopathy (PSE); (13) data collection. The study protocol and consent forms were approved before the start of the study and at regular intervals thereafter by the UCSD Human Subjects Committee (Institutional Review Board). Figure 1 is a Consort flow Diagram that shows the overall design and conduct of the RCT [16,17].

\section{Liver Transplantation in the Randomized Controlled Trial}

Patients were evaluated by the UCSD liver transplantation program during the index hospital admission and intermittently during follow-up. They underwent extensive evaluation for liver transplantation if and when they exhibited progressive liver failure. 13 survivors of emergency treatment of BEV developed progressive liver failure and underwent complete LT evaluation, 7 from the EST group and 6 from the EPCS group.

\section{Unrandomized Portacaval Shunt Patients}

Beginning in 1978 when LT became available to us, we performed portacaval shunt (PCS) for BEV in 1300 cirrhotic patients at UCSD Medical Center Hospitals and the San Diego Veterans Administration Hospital. Patients were studied prospectively according to a welldefined protocol with on-line data collection to determine the indications for subsequent LT. The diagnostic work-up was identical in the unrandomized patients and the RCT patients. From 1978 until the start of our RCT in 1988, EPCS was performed for acute variceal bleeding within 8 hours of initial contact in 600 unselected patients, all comers included. Elective PCS was done over a period of 20 years in 700 selected patients referred to us only after recovery from one or more bouts of BEV elsewhere. Follow-up rate was $100 \%$ at 5 years and $97 \%$ at 10 years.

\section{Statistical Analysis}

The survival rates in the EST and EPCS groups, and in the subgroups determined by the Child's risk class were calculated and plotted using the Kaplan-Meier method, and compared using the log-rank test. Statistical comparisons between the EST and EPCS groups in the RCT were performed as follows: The proportion of subjects referred for LT evaluation, the proportion approved for LT, and the diagnosis of the LT candidates, were compared using Fisher's exact test (FET). The time after entry in the RCT to LT evaluation and the duration of survival after evaluation and since entry were compared using the logrank test. The MELD at time of LT was evaluated using the Wilcoxon rank test, and the Child's risk class at LT evaluation using Fisher's exact test. Statistical significance was considered at the 0.05 level.

\section{RESULTS}

\section{Outcome Data in Randomized Controlled Trial}

The clinical characteristics of the 211 patients involved in the RCT were described in our recent publications, including findings on upper endoscopy and liver biopsy, results of laboratory blood tests, data on rapidity of therapy, data on control of bleeding, operative and endoscopic data and data on quality of life $[14,15]$. There were no significant differences between the EST and EPCS groups in any important characteristics of cirrhosis. Child's risk classes on study entry in the EST and EPCS groups, respectively, were $30 \%$ and $25 \%$ in A, $43 \%$ and $47 \%$ in B, and $26 \%$ and $29 \%$ in C. Overall Child's quantitative point scores in the two groups were essentially identical. Three-fourths of the patients had advanced liver disease on admission, often categorized as "end-stage". Histologic proof of cirrhosis was obtained in all patients. Mean and median times from onset of bleeding to start of EST and EPCS were less than $24 \mathrm{hr}$. Excluding indeterminate deaths within 14 days from causes 
other than bleeding, EST achieved permanent long-term control of bleeding in only $20 \%$ of patients. In contrast, EPCS promptly and permanently controlled bleeding in every patient. Patients in the EST" group required significantly more units of packed red blood cells than those in the EPCS group because of continued or recurrent BEV.

\section{Survival in the Randomized Controlled Trial}

Figure 2 shows 15-yr Kaplan-Meier estimated survival plots for the EST and EPCS groups. There were highly significant differences in the survival rates of the two study groups at all time intervals $(\mathrm{p}<0.001)$. As expected, the survival rate was related to the severity of hepatic disease at the time of entry in the study, as expressed by Child's risk classes. Survival rates at all time intervals and in all Child's classes were significantly higher after EPCS than after EST. Moreover, EPCS resulted in substantial long-term survival of patients in Child's risk class $\mathrm{C}$ who had the most advanced cirrhosis of the liver. Persistent or recurrent BEV was the main cause of death in $44 \%$ of the EST patients, but in none of the patients treated by EPCS. Hepatic failure was responsible for $28 \%$ of the deaths in the EST group and $33 \%$ of the much smaller number of deaths in the EPCS group.

\section{Liver Transplantation in the Randomized Controlled Trial}

Table 1 summarizes data on the 13 patients who were ultimately referred for LT in our RCT. They constituted only $6 \%$ of the total patients entered into the RCT. 7 patients were approved for LT, but only 4 patients, all in the EST group, underwent LT. 6 patients were denied LT because of continued alcoholism or substance abuse, or non-USA resident status. All patients referred for LT evaluation had advanced cirrhosis in Child's class C or B. with a mean MELD score of 21.

Figure 2 shows Kaplan-Meier survival plots of the patients who underwent LT and the patients who were evaluated for but did not undergo LT, and compares their survival curves with the Kaplan-Meier curves showing the overall survival of patients who received EST or EPCS in the RCT. As was true of the overall survival of patients in the EPCS group, patients from this group who were evaluated for LT lived more than 8 years, even though they did not undergo LT. In contrast, as was true of the EST group in general, patients from this group who were evaluated for or underwent LT had a mean survival of 1.5 years or less.

\section{Liver Transplantation in the Unrandomized Portacaval Shunt Patients}

All 1300 unrandomized patients had cirrhosis proven by biopsy and bleeding varices proven by endoscopy. The cause of cirrhosis in $85 \%$ of the patients was chronic alcoholism without or with serologically proven chronic viral hepatitis. Quantitative Child's risk classes were A, $11 \%$; B, 50\%; and C, 39\%. Serious risk factors on admission or past history were ascites in $64 \%$, jaundice in 58\%, PSE in $36 \%$ and severe muscle wasting in $49 \% .90 \%$ of the patients had end-stage cirrhosis. Indications for LT after PCS were declining liver function in the presence of end-stage cirrhosis. Only patients who had been abstinent for 6 or more months were accepted as candidates for LT.

Only 50 of the 1300 patients (3.8\%) were referred for LT. 19 of the 1300 (1.5\%), all in Child's class B (26\%) or C (74\%), underwent LT. 12 were EPCS patients and 7 were elective PCS patients. The remaining 31 patients were rejected for LT because of resumption of alcoholism, substance abuse, infection, and various other serious comorbidity.

The 30-day, 5-year, and 10-year survival rates, respectively, were $83 \%, 67 \%$, and $67 \%$ after emergency PCS, and 98\%, 76\%, and 71\% after elective PCS. Following LT, the 30-day and 5 -year survival rates were $89 \%$ and $53 \%$, respectively. The 5-year survival rate of the 31 patients who were proposed but rejected for LT was only 7\%. PCS did not increase the 
mortality rate or complications of subsequent LT compared with the reports in the literature of that time period and with a large group of unshunted cirrhotic patients who underwent LT. Figure 4 compares 5-year Kaplan-Meier survival plots of the 1300 PCS patients with both the PCS patients who underwent LT and the PCS patients who were rejected for LT.

Regular follow-up was achieved in $100 \%$ of the patients for 5 years and $97 \%$ for 10 years. During those time periods, all but 2 of the 1300 patients remained free of recurrent BEV and the PCS remained permanently patent in all but 2 patients (99.8\%). Recurrent PSE was observed in $10 \%$ of the patients. Liver function improved in $76 \%$ of the patients and, after 5 years, only $6 \%$ of the patients were in Child's class C, compared to $39 \%$ on admission.

\section{DISCUSSION}

Comment is warranted about two widely used emergency measures that were not included in our RCT, namely endoscopic variceal ligation (EVL) and transjugular intrahepatic portosystemic shunt (TIPS). In 1988 when the San Diego BEV Study was initiated, EST was a mainstay of therapy of BEV and the sole form of endoscopic therapy in use. More recently, elective therapy with endoscopic variceal ligation (EVL) has replaced EST in some centers as a result of several studies showing more rapid eradication of varices, lower rates of recurrent bleeding, and fewer complications [22]. However, replacement of EST by EVL increasingly has been questioned [22-25]. In a 2003 survey of 93 gastroenterologists who treated 725 patients in various centers, EST was used more frequently than EVL for control of variceal bleeding, and as frequently as EVL for initial control of acute bleeding [23]. Several recent trials have reported a significantly higher failure rate with band ligation of actively bleeding varices, and an overall higher recurrence rate of varices treated by EVL [22,25]. Moreover, EST has been reported to be more cost-effective if active variceal hemorrhage is present at the index endoscopy procedure [24]. It is noteworthy that none of 9 randomized controlled trials observed a statistically significant difference in survival rate between EVL and EST [22]. In a recent meta-analysis of emergency EST in 40 trials involving 4031 patients reported by Triantos and colleagues in 2006, there was no statistically significant difference in survival rate between EVL and EST [25]. The authors concluded that "the conclusive evidence for substituting banding ligation or the combination of vasoconstrictors with sclerotherapy as better therapeutic approaches has not been provided in randomized trials. Sclerotherapy can remain a gold standard in variceal bleeding...". At the time when EVL was introduced at our institution, we were well into our RCT and made the decision not to change from EST to EVL.

With regard to TIPS, our RCT was initiated well before clinical use of TIPS was introduced. Moreover, as we and others have pointed out previously. TIPS has a high rate of stenosis and occlusion, a resultant high incidence of portal-systemic encephalopathy (PSE), and limited durability. The TIPS occlusion rate has been reduced by the recent introduction of the polytetrafiuorethylene-coated stent, but the rates of occlusion and PSE are still much higher than the incidences of these serious complications following portacaval shunt in all of our studies.

One purpose of the San Diego BEV Study that involved 211 randomized patients, and the supplementary analysis of the 1300 unrandomized cirrhotic patients who underwent PCS for $\mathrm{BEV}$ was to answer several questions about the role of emergency treatment of BEV in subsequent LT. In so doing it is important to recognize that to date no RCTs have been reported in which the relationship of BEV to LT has been examined prospectively. Since our RCT involved a comparison of EST and EPCS, the first question is: what is the role of endoscopic therapy of BEV in patients who might subsequently need LT? Several experienced workers at liver transplantation centers have proposed that EST or endoscopic 
variceal ligation $(\mathrm{EVL})$ is the first line of treatment for $\mathrm{BEV}$, and that "there are ample data in the literature to support long-term sclerotherapy as the treatment of first choice for bleeding esophageal varices" $[11,12,26]$. The results of our RCT contradict this proposal. EST achieved permanent long-term control of bleeding in only $20 \%$ of unselected consecutive patients. The 5-year survival rate of patients treated by EST was only $21 \%$, and median survival was less than 3 years, even with rescue PCS. The reasons why LT was not considered in more patients in the EST group arc that death from recurrent bleeding in $44 \%$ of patients, frequent PSE often due to non-compliance as well as to recurrent bleeding, and social issues such as continued alcoholism, drug abuse and non-USE residence status obviated considerations of LT.

The second question is: how often following an episode of acute BEV in patients with advanced cirrhosis is LT required? The results of our study indicate that LT is seldom required following control of bleeding by PCS. In our RCT, only $6 \%$ of the patients were referred for LT, only $3 \%$ were approved for LT, and only 4 patients (2\%) underwent LT. Of our 1300 unrandomized patients with PCS, only $3.8 \%$ of the patients were referred for LT, and only 19 patients $(1.5 \%)$ underwent LT. Furthermore and most important, if recurrent $\mathrm{BEV}$ is prevented, as was true in $100 \%$ of the PCS patients, both randomized and unrandomized, prolonged survival occurs, equal to or better than survival following LT. 30day and 5-year survival rates were 87\% and 73\%, respectively, following EPCS in 105 patients in the RCT, 83\% and 67\%, respectively, following EPCS in 600 unrandomized patients, and $98 \%$ and $71 \%$, respectively, following elective PCS in 700 unrandomized patients. Survival rates following LT during the period 1988 to 2001 in 46,940 patients reported by the United Network for Organ Sharing (UNOS), were $74.5 \%$ at 1 year, $67.4 \%$ at 3 years and $62.7 \%$ at 5 years [27]. Clearly, the 5-year survival rate following PCS (73\%, $67 \%$ and $71 \%$ ) was higher than that of the UNOS LT survival rate (62.7\%). It is noteworthy that close to one-half of the patients in the RCT (46\%) were alive 15 years after EPCS.

The third question is: should transplant surgeons avoid portacaval shunts or surgical decompressive procedures that involve the hepatic hilum in potential LT candidates? There are numerous statements in the transplantation literature urging avoidance of PCS and strong recommendations to that effect from some recognized transplantation centers [11,12. 23,2830]. However, there are no valid, representative data from prospective studies, randomized or unrandomized, that support such a proposal. Our studies indicate that PCS is the most effective treatment of BEV, invariably prevents recurrence of bleeding, and achieves longterm survival so that the vast majority of patients do not require LT.

The fourth question is: do portosystemic shunts and, particularly, portacaval shunt, affect the outcome of LT? Our RCT in which only 4 of the 211 patients underwent LT does not provide sufficient data to answer this question. However, the survival rate of the 19 unrandomized patients who underwent LT was $89 \%$ after 30 days and $53 \%$ after 5 years, which was not significantly different from the survival rates for LT reported by UNOS. PCS did not increase the mortality rate or complications of subsequent LT. Added to the data from our study-are at least 10 reports of retrospective studies in the literature that concluded that portosystemic shunts do not affect the results of subsequent LT [11-13,29-36]. That conclusion has not been contradicted by reported studies.

Liver transplantation plays a central role in the treatment of cirrhosis of the liver. Nevertheless, there are a number of limitations on the use of this important therapeutic measure as a cure for cirrhosis [37]. The most important limitation is unavailability of donor livers. In year 2008 there were 17,167 candidates on the waiting list for LT at the beginning of the year and 16,538 on the waiting list at the end of the year (based on OPTN data as of 5/31/09). 6,319 candidates or 37\% received LT. 2,456 patients died or deteriorated while 
awaiting LT. The median waiting time for LT in 2002 was 974 days and, although the wait was shorter in 2005, it was still 321 days [27]. Furthermore, numerous patients referred for LT have been disqualified for various reasons. Of the patients referred for LT evaluation, $46 \%$ in the RCT and $62 \%$ in the unrandomized series were turned down for valid reasons including continued alcoholism, drug abuse, and non-USA resident status. Additionally, the costs of LT are substantial. Direct costs of care, as reflected by charges for patients who underwent EPCS in our RCT including costs of lifelong follow-up, averaged a total of $\$ 150,400$ or $\$ 39,400$ per year. In contrast, the mean cost of LT for cirrhosis in adult patients in 2008 , including 180 days of post-transplant care, averaged $\$ 523.400$, which is more than 3 times the lifelong average cost of EPCS [27]. Finally, third-party insurance coverage for emergency treatment of BEV such as EPCS has been readily obtainable, while coverage for LT is sometimes difficult to obtain. At one of our institutions, of 182 patients referred for LT from January through July, 2009, 11\% were denied LT because of insurance issues.

The results of EPCS in our RCT are generally superior to the results of other reported studies of emergency treatment, all of which have been retrospective and unrandomized. We believe there are several reasons for the difference in outcome. Firstly, our RCT was an organized, community-wide endeavor in which physicians rapidly referred patients from hospitals in 4 neighboring counties to UCSD Medical Center for treatment. Secondly, the diagnostic workup was simplified by eliminating time-consuming, often invasive and unnecessary studies so that the entire diagnostic work-up was completed at the bedside within a mean 3.1 to 4.4 hours of initial contact. Third, with a few minor exceptions, definitive therapy was initiated within 8 hours of initial contact. Fourth, EPCS was performed under the direction of one or the other of two senior faculty surgeons who had extensive operative experience with EPCS. Fifth, concerted efforts were made, with the regular help of dieticians and nurses, to control dietary protein intake and to achieve permanent abstinence from alcohol. Sixth, regular follow-up was $100 \%$ and was for 9.4 to more than 10 years until death. Seventh, the direct side-to-side PCS remained permanently patent and functioning in $98 \%$ of patients, a rate that is consistent with our past experience with more than 2500 side-to-side PCS, with a failure rate of $2 \%$, substantially lower than reported shunt occlusion rates of $12 \%$ to $29 \%$ for conventional portal-systemic shunts, $14 \%$ to $23 \%$ for distal splenorenal shunts [38], $24 \%$ to $53 \%$ for mesocaval interposition shunts [39-41], and greater than 50\% for transjugular intrahepatic portosystemic shunts (TIPS) [42-47].

In conclusion, in this RCT of emergency treatment of acute BEV in 211 patients with cirrhosis, supplemented by analyses of 1300 unrandomized patients treated by portacaval shunt, prospective data indicate clearly that BEV by itself should not be considered an indication for LT. Moreover, the data show that PCS should be considered a first line treatment for BEV since it promptly and permanently stopped variceal bleeding, was accomplished with a relatively low (15\%) incidence of subsequent PSE, and produced longterm survival rates equal or superior to those produced by LT. Furthermore, PCS did not increase the mortality rate or complications in the small number of patients who ultimately required LT, a finding that was confirmed by at least 10 retrospective studies reported in the literature. The importance of these results is underscored by the severe shortage of donor organs, the much higher cost of LT compared to PCS, and the substantial difficulties in obtaining insurance coverage for LT in some patients in the population that develops BEV due to cirrhosis.

\section{Acknowledgments}

1R01 DK41920 from the National Institutes of Health and a grant from the Surgical Education and Research Foundation (501(c)(3)). 
We thank the many residents in the Department of Medicine and the Department of Surgery at UCSD Medical Center who played a major role in the care of patients in this study. We thank the many physicians practicing in the counties of San Diego, Imperial, Orange, and Riverside, who helped with patient recruitment, referral, and longterm follow-up. This work was supported in party by Health Resources and Services Administration contract 234-2005-370011C. The content is the responsibility of the authors alone and does not necessarily reflect the views or policies of the Department of Health and Human Services, nor does mention of trade names, commercial products, or organizations imply endorsement by the U.S. Government.

\section{ABBREVIATIONS}

$\begin{array}{ll}\text { BEV } & \text { bleeding esophageal varices } \\ \text { LT } & \text { liver transplantation } \\ \text { RCT } & \text { randomized clinical trial } \\ \text { EST } & \text { endoscopic sclerotherapy } \\ \text { EPCS } & \text { emergency portacaval shunt } \\ \text { PSE } & \text { portal-systemic encephalopathy } \\ \text { PCS } & \text { portacaval shunt } \\ \text { UGI } & \text { upper gastrointestinal } \\ \text { ICU } & \text { intensive care unit } \\ \text { MELD } & \text { Model for End-stage Liver Disease } \\ \text { EVL } & \text { endoscopic variceal ligation } \\ \text { TIPS } & \text { transjugular intrahepatic portosystemic shunt }\end{array}$

\section{References}

1. Orloff, MJ. Portal hypertension and portacaval shunt. In: Souba, W.; Wilmore, D., editors. Surgical Research. Harcourt Brace; San Diego: 2001. p. 637-701.

2. Graham DY, Smith H. The course of patients after variceal hemorrhage. Gastroenterology 1981;80:800-809. [PubMed: 6970703]

3. Smith JL, Graham DY. Variceal hemorrhage: a critical evaluation of survival analysis. Gastroenterology 1982;82:968-973. [PubMed: 7037525]

4. Burroughs AK, Mezzanotte G, Phillips A, McCormick PA, McIntyre N. Cirrhotics with variceal hemorrhage: the importance of the time interval between admission and the start of analysis for survival and rebleeding rates. Hepatology 1969;9:801-807. [PubMed: 2785478]

5. Bornman PC, Krige JE, Terblanche J. Management of oesophageal varices. Lancet 1994;353:1079_ 1084. [PubMed: 7909104]

6. Khan S, Tudur Smith C, Williamson P, Sutton R. Portosystemic shunts versus endoscopic therapy for variceal rebleeding in patients with cirrhosis. Cochrane Database of Systematic Reviews 2006; (1):CD000553. Art. No. CD000553. Pub 2. 10.1002/14651858

7. Orloff MJ, Duguay LR, Kosta LD. Criteria for selection of patients for emergency portacaval shunt. Am J Surg 1977;134:146-152. [PubMed: 879407]

8. Mikkelsen WP. Therapeutic portacaval shunt. Preliminary data on controlled trial and morbid effects of acute hyaline necrosis. Arch Surg 1974;108:302-305. [PubMed: 4544310]

9. Terblanche J, Burroughs AK, Hobbs KEF. Controversies in the management of bleeding oesophageal varices. N Engl J Med 1989;320:1393-1398. [PubMed: 2654633]

10. D'Amico G, Pagliaro L, Bosch J. The treatment of portal hypertension: a meta-analytic review. Hepatology 1995;22:332-354. [PubMed: 7601427]

11. Iwatsuki S, Starzl TE, Todo S, Gordon RD, Tzakis AG, Marsh JW, Makowka L. Liver transplantation in the treatment of bleeding esophageal varices. Surgery 1988;104:697-705. [PubMed: 3051474] 
12. Reyes J, Iwatsuki S. Current management of portal hypertension with liver transplantation. Advances in Surgery 1992;25:189-208. [PubMed: 1536096]

13. Bismuth H, Adam R, Mathur S, Sherlock D. Options for elective treatment of portal hypertension in cirrhotic patients in the transplantation era. Am J Surg 1990;160:105-110. [PubMed: 2368870]

14. Orloff MJ, Isenberg JI, Wheeler HO, Haynes KS, Jinich-Brook H, Rapier R, et al. Randomized trial of emergency endoscopic sclerotherapy versus emergency portacaval shunt for acutely bleeding esophageal varices in cirrhosis. J Am Coll Surg 2009;209:25-40. [PubMed: 19651060]

15. Orloff MJ, Isenberg JI, Wheeler HO, Haynes KS, Jinich-Brook H, Rapier R, et al. Portal-systemic encephalopathy in a randomized controlled trial of endoscopic sclerotherapy versus emergency portacaval shunt treatment of acutely bleeding esophageal varices in cirrhosis. Ann Surg 2009;250:598-610.

16. Moher D, Schulz KF, Altman D. The CONSORT statement: revised recommendations for improving the quality of reports of parallel-group randomized trials. JAMA 2001;285:1987-1991. [PubMed: 11308435]

17. Altman DG, Schulz KF, Moher D, Egger M, Davidoff F, Elbourne D, et al. The revised CONSORT statement for reporting randomized trials: explanation and elaboration. Ann Intern Med 2001;134:663-694. [PubMed: 11304107]

18. Orloff MJ, Orloff MS, Orloff SL, Rambotti M, Girard B. Three decades of experience with emergency portacaval shunt for acutely bleeding esophageal varices in 400 unselected patients with cirrhosis of the liver. J Am Coll Surg 1995;180:257-272. [PubMed: 7874335]

19. Child, CG., III; Turcotte, JG. Surgery and portal hypertension. In: Child, CG., III, editor. The Liver and Portal Hypertension. W.B. Saunders; Philadelphia: 1964. p. 1-85.

20. Campbell DP, Parker DE, Anagnostopoulos CE. Survival prediction in portacaval shunt: a computerized statistical analysis. Am J Surg 1973;126:748-751. [PubMed: 4543312]

21. Orloff, MJ.; Orloff, SL.; Orloff, MS. Portacaval shunts: side-to-side and end-to-side. In: Clavien, P-A.; Saar, MG.; Fong, Y., editors. Atlas of Upper Gastrointestinal and Hepato-Pancreato-Biliary Surgery. Springer-Verlag; Berlin Heidelberg: 2007. p. 687-702.

22. Krige JE, Shaw JM, Bornman PC. The evolving role of endoscopic treatment of esophageal varices. Wld J Surg 2005;29:966-973.

23. Sorbi D, Gostout CJ, Peura D, Johnson D, Lanza F, Foutch PG, et al. An assessment of the management of acute bleeding varices: a multicenter prospective member-based study. Am J Gastroenterol 2003;98:2424-2434. [PubMed: 14638344]

24. Gralnek IM, Jensen DM, Kovacs TOG, Jutabha R, Gornbein J, Cheng S, et al. The economic impact of esophageal variceal hemorrhage: cost-effectiveness implications of endoscopic therapy. Hepatology 1999;29:44-50. [PubMed: 9862848]

25. Triantos CK, Goulis J, Patch D, Papatheodoridis GV, Leandro G, Samonakis D, et al. An evaluation of emergency sclerotherapy of varices in randomized trials: looking the needle in the eye. Endoscopy 2006;38:797-808. [PubMed: 17001564]

26. Hillert C, Fischer L, Broering DC, Rogiers X. Liver transplantation in patients with liver cirrhosis and esophageal bleeding. Langenbecks Arch Surg 2003;388:150-154. [PubMed: 12756568]

27. Hauboldt, RH.; Hanson, SG.; Bernstein, GR. Milliman Research Report. Apr. 2008 U.S. organ and tissue transplant cost estimates and discussion; p. 1-17.

28. Brems JJ, Hiatt JR, Klein AS, Milis JM, Colonna JO, Quinones-Baldrich WJ, et al. Effect of a prior portosystemic shunt on subsequent liver transplantation. Ann Surg 1989;209:51-56. [PubMed: 2642690]

29. Jenkins RL, Gedaly R, Pomposelli JJ, Pomfret EA, Gordon F, Lewis WD. Distal splenorenal shunt: role indications and utility in the era of liver transplantation. Arch Surg 1999;134:416-420. [PubMed: 10199316]

30. Dell'Era A, Grande L, Barros-Schelotto P, Turnes J, Fuster J, Charco R, et al. Impact of prior portosystemic shunt procedures on outcome of liver transplantation. Surgery 2005;137:620-625. [PubMed: 15933628]

31. Mazzaferro V, Todo S, Tzakis A, Stieber AC, Makowka L, Starzi TE. Liver transplantation in patients with previous portasystemic shunt. Am J Surg 1990;160:111-116. [PubMed: 2368871] 
32. Langnas AN, Marujo WC, Stratta RJ, Donovan JP, Sorrell MF, Rikkers LF, Shaw BW Jr. Influence of a prior porta-systemic shunt on outcome after liver transplantation. Am J Gastroenterol 1992;87:714-718. [PubMed: 1590306]

33. Turrion VS, Mora NP, Cofer JB, Solmon H, Morris CA, Gonwa TA, et al. Retrospective evaluation of liver transplantation for cirrhosis: a comparative study of 100 patients with or without previous porto-systemic shunt. Transplant Proc 1991;23:1570-1. [PubMed: 1989295]

34. Aboujaoude MM, Grant DR, Ghent CN, Mimeault RE, Wall WJ. Effect of portasystemic shunts on subsequent transplantation of the liver. Surg Gynecol Obstet 1991;172:215-219. [PubMed: 1994497]

35. Rubio Gonzalez EE, Moreno Planas JM, Jimenez Garrido MC, Lucena de la Poza JL, Martinez Arrieta F, Cuervas-Mons V, Sanchez Turrion V. Results of liver transplantation in patients with previous portosystemic shunts. Transplant Proc 2005;37:1491-2. [PubMed: 15866651]

36. Ho K-S, Lashner BA, Emond JC, Baker AL. Prior esophageal variceal bleeding does not adversely affect survival after orthotopic liver transplantation. Hepatology 1993;18:66-72. [PubMed: 8325623]

37. Anantharaju A, Van Thiel DH. Liver transplantation for alcoholic liver disease. Alcohol Research and Health 2003;27:257. [PubMed: 15535454]

38. Grace ND, Conn HO, Resnick RH, Groszmann RJ, Atlerbury CE, Wright SC, et al. Distal splenorenal versus portal systemic shunts after haemorrhage from varices: a randomized controlled trial. Hepatology 1988;8:1475-1481. [PubMed: 3056820]

39. Terpstra OT, Ausema B, Bruining HA, Lameris JS, Reuvers CB, Schalm SW, et al. Late results of mesocaval interposition shunting for bleeding oesophageal varices. Br J Surg 1987;74:787-780. [PubMed: 3499203]

40. Smith RB, Warren WD, Salam AA, Millikan WJ, Ansley JD, Galambos JT, et al. Dacron interposition shunts for portal hypertension. An analysis of morbidity correlates. Ann Surg 1980;192:9-17. [PubMed: 6447485]

41. Fletcher MS, Dawson JL, Williams R. Long term follow-up of interposition mesocaval shunting in portal hypertension. Br J Surg 1981;68:485-487. [PubMed: 6972793]

42. Helton WS, Belshaw A, Althaus S, Park S, Coldwell D, Johansen K. Critical appraisal of the angiographic portacaval shunt (TIPS). Am J Surg 1993;165:566-571. [PubMed: 8488938]

43. LaBerge JM. Transjugular intrahepatic portosystemic shunt-role in treating intractable variceal bleeding, ascites, and hepatic hydrothorax. Clin Liver Dis 2006;10:583-598. [PubMed: 17162229]

44. Bayer TD, Haskal ZJ. The role of transjugular intrahepatic shunt in the management of portal hypertension. Hepatology 2005;41:386-400. [PubMed: 15660434]

45. Sanyal AJ, Freedman AM, Shiftman ML, Purdum PP, Luketic VA, Cheatham AK. Portosystemic encephalopathy after transjugular intrahepatic portosystemic shunt: results of a prospective controlled study. Hepatology 1994;20:46-55. [PubMed: 8020904]

46. Rössle M, Haag K, Ochs A, Hauenstein KH, Deibert P, Siegerstetter V, et al. The transjugular intrahepatic portosystemic stent-shunt procedure for variceal bleeding. N Engl J Med 1994;330:165-171. [PubMed: 8264738]

47. Jalan R, Elton RA, Redhead DN, Finlayson NDC, Hayes PC. Analysis of prognostic variables in the prediction of mortality, shunt failure, variceal rebleeding and encephalopathy following the transjugular intrahepatic portosystemic stent-shunt for variceal haemorrhage. J Hepatol 1995;23:123-128. [PubMed: 7499782] 


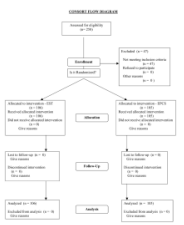

Figure 1.

The overall design and conduct of the prospective randomized controlled trial is shown in a Consort Flow Diagram [18,19]. 


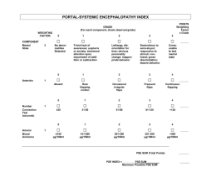

Figure 2.

Kaplan-Meier estimates of survival of patients in the RCT who were evaluated for and did or did not undergo liver transplantation. The overall survival of patients in the EST and EPCS groups is shown for comparison. 

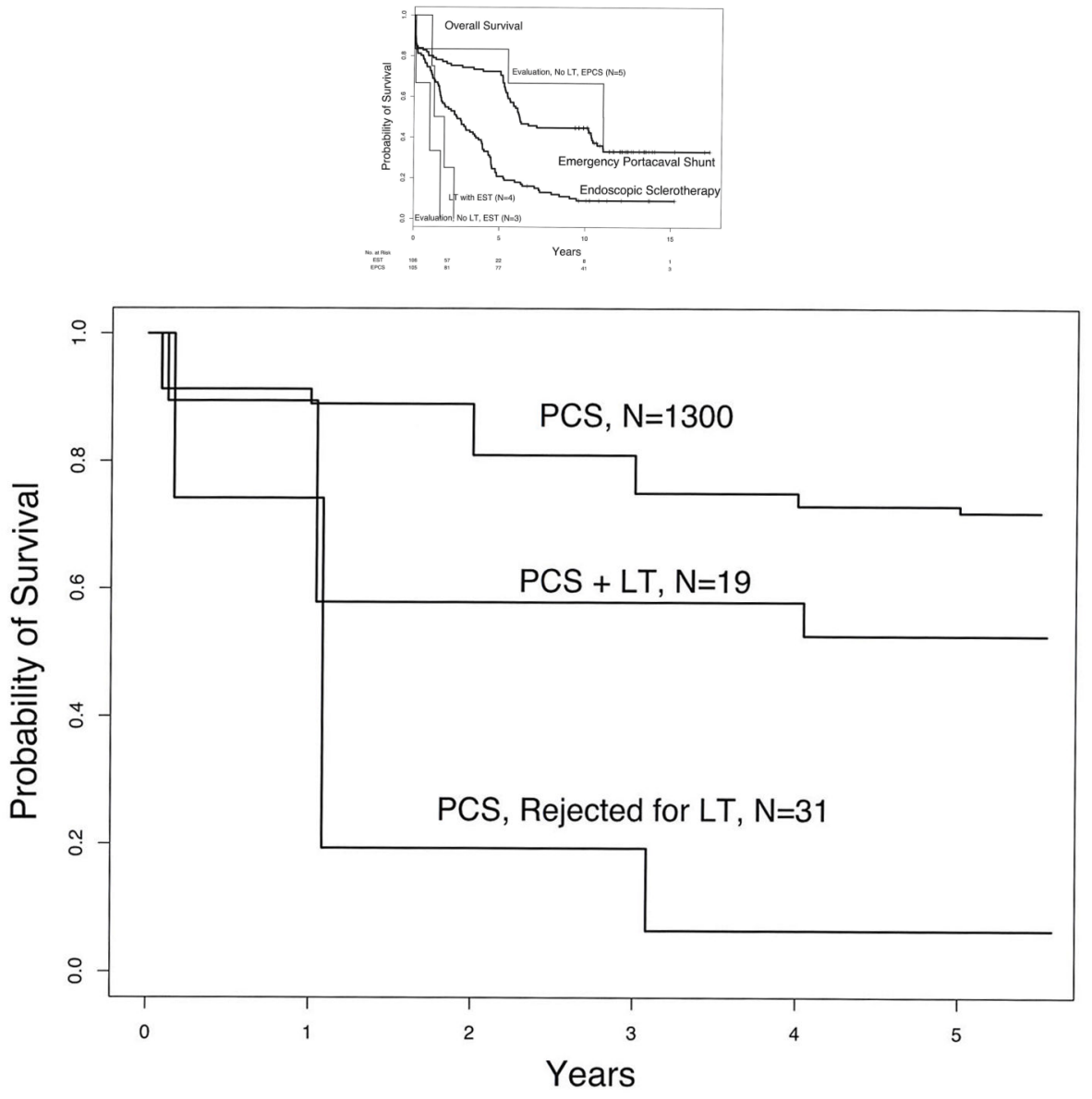

Figure 3.

Kaplan-Meier estimates of survival of 1300 unrandomized PCS patients including survival of patients who underwent LT and patients who were rejected for LT. 
Table 1

Liver transplantation (LT) in randomized controlled trial of EST versus EPCS for BEV in cirrhosis

\begin{tabular}{|c|c|c|c|c|}
\hline & EST (n=106) & $\operatorname{EPCS}(n=105)$ & TOTAL $(n=211)$ & P Value \\
\hline Referred for LT Evaluation - n (\%) & $7(6.6 \%)$ & $6(5.7 \%)$ & $13(6.2 \%)$ & 1.0 \\
\hline Diagnosis of LT Candidates $-\mathrm{n}(\%)$ & & & & 0.17 \\
\hline Alcoholism & $3(2.8 \%)$ & $1(1.0 \%)$ & $4(1.9 \%)$ & \\
\hline Hepatitis & $2(1.9 \%)$ & 0 & $2(0.9 \%)$ & \\
\hline Alcoholism and hepatitis & 0 & $3(2.9 \%)$ & $3(1.4 \%)$ & \\
\hline Cryptogenic & $1(0.9 \%)$ & $2(1.9 \%)$ & $3(1.4 \%)$ & \\
\hline Autoimmune & $1(0.9 \%)$ & 0 & $1(0.5 \%)$ & \\
\hline \multicolumn{5}{|l|}{ Results of LT Evaluation } \\
\hline LT performed & 4 & 0 & 4 & \\
\hline LT approved but not done & 2 & 1 & 3 & \\
\hline LT denied & 1 & 5 & 6 & \\
\hline Reasons for denial: & 0 & & & \\
\hline Continued alcoholism & 0 & 3 & 3 & \\
\hline Continued drug abuse & 0 & 1 & 1 & \\
\hline Non-US resident & 1 & 0 & 1 & \\
\hline Continued drug abuse + Non-US resident & 0 & 1 & 1 & \\
\hline $\begin{array}{l}\text { Time after entry in RCT to final LT evaluation: } \\
\text { Mean (range), in years: }\end{array}$ & $1.00(\mathrm{n}=7)(0.04-2.35)$ & $2.70(\mathrm{n}=6)(0.02-6.74)$ & $1.47(0.02-6.74)$ & 0.23 \\
\hline Approved for $\mathrm{LT}-\mathrm{n}(\%)$ & $6(5.6 \%)$ & $1(1.0 \%)$ & $7(3.3 \%)$ & $0.050^{*}$ \\
\hline Time on waiting list: Mean (range), in years & $0.162(\mathrm{n}=6)(0.00-0.59)$ & $8.96(\mathrm{n}=1)$ & & \\
\hline Died on waiting list + time & 0 & 0 & & \\
\hline Survival after LT ( $\mathrm{n}=4$ ) Mean (range), yrs & $0.204(0.001-0.805)$ & NA & $0.204(0.001-0.805)$ & NA \\
\hline $\begin{array}{l}\text { Survival after evaluation, no LT Mean (range), } \\
\text { years }(n=9)\end{array}$ & $\begin{array}{c}\mathrm{n}=3 \\
0.237(0.047-0.586)\end{array}$ & $\begin{array}{c}\mathrm{n}=6 \\
6.027(0.017-12.73)\end{array}$ & $\begin{array}{c}\mathrm{n}=9 \\
4.097(0.017-12.73)\end{array}$ & $0.040^{*}$ \\
\hline Survival since entry: Mean (range), yrs ( $n=9$ ) & $1.266(0.088-2.357)$ & $8.720(0.033-13.140)$ & $4.706(0.033-13.140)$ & $0.008^{*}$ \\
\hline MELD at time of LT evaluation: Mean (range) & $\begin{array}{c}n=7 \\
21.3(7-39)\end{array}$ & $\begin{array}{c}\mathrm{n}=6 \\
20.2(7-36)\end{array}$ & $\begin{array}{c}\mathrm{n}=13 \\
20.8(7-39)\end{array}$ & 0.89 \\
\hline MELD at evaluation in $4 \mathrm{LT}$ patients Mean (range) & $\begin{array}{c}\mathrm{n}=4 \\
20.8(17-27)\end{array}$ & $\mathrm{n}=0$ & $\begin{array}{c}\mathrm{n}=4 \\
20.8(17-27)\end{array}$ & NA \\
\hline
\end{tabular}




\begin{tabular}{|l|c|c|c|c|}
\hline & EST $(\mathbf{n = 1 0 6})$ & EPCS $(\mathbf{n = 1 0 5})$ & TOTAL $(\mathbf{n = 2 1 1})$ & P Value \\
\hline Child's Class at LT evaluation (n=13) & $\begin{array}{c}\mathrm{A}=0 \\
\mathrm{~B}=1\end{array}$ & $\mathrm{~A}=0$ & $\mathrm{~B}=4$ \\
$\mathrm{C}=6$ & $\mathrm{C}=2$ & $\mathrm{~A}=0$ & 0.10 \\
& $\mathrm{~B}=5$ & & \\
& & $\mathrm{C} 8$ & \\
\hline
\end{tabular}

